\title{
Chemosensory Cues for Mosquito Oviposition Site Selection
}

\author{
ALI AFIFY AND C. GIOVANNI GALIZIA ${ }^{1}$ \\ Department of Neurobiology, University of Konstanz, Universitatsstraße 10, D-78457, Konstanz, Germany.
}

\begin{abstract}
Gravid mosquitoes use chemosensory (olfactory, gustatory, or both) cues to select oviposi tion sites suitable for their offspring. In nature, these cues originate from plant infusions, microbes, mosquito immature stages, and predators. While attractants and stimulants are cues that could show the availability of food (plant infusions and microbes) and suitable conditions (the presence of conspecifics), repellents and deterrents show the risk of predation, infection with pathogens, or strong competition. Many studies have addressed the question of which substances can act as positive or negative cues in different mosquito species, with sometimes apparently contradicting results. These studies often differ in species, substance concentration, and other experimental details, making it difficult to compare the results. In this review, we compiled the available information for a wide range of species and substances, with particular attention to cues originating from larval food, immature stages, predators, and to syn thetic compounds. We note that the effect of many substances differs between species, and that many substances have been tested in few species only, revealing that the information is scattered across species, substances, and experimental conditions.
\end{abstract}

KEY WORDS mosquito, odor, olfactory, gustatory, oviposition

\section{Introduction}

Mosquito aquatic stages are restricted in their move ment and are not able to change their habitats at the larval and pupal stage. Therefore, gravid females should carefully choose oviposition sites. The availabil ity of food, absence of predators, and low levels of com petition are among the likely factors sought for.

Olfactory cues range relatively long distances and could convey information for the oviposition seeking gravid females about the substrate's suitability. Therefore, mosquitoes depend mainly on olfactory cues such as the smell of nutrients, cues from predators or other mosquito larvae in the water to decide whether this water is suit able for their larvae or not. For short range substrate evaluation, mosquitoes might use a combination of gusta tory, tactile, and even visual cues (Bentley and Day 1989). Here, we focus on the chemosensory component.

An "oviposition attractant" is a substance that causes gravid females to make oriented flight toward the ovi position substrate while an "oviposition stimulant" is a substance that elicits the oviposition behavior after landing on the substrate. On the other hand, a "repel lent" is a substance that encourages mosquito to make oriented flight away from the oviposition substrate while a "deterrent" is a substance that inhibits oviposi tion behavior (Clements 1999). Hence, attractants and repellents are cues that affect mosquito behavior over a long distance and are exclusively olfactory, while

\footnotetext{
${ }^{1}$ Corresponding author, e-mail: Giovanni.Galizia@uni-konstanz.de.
}

stimulants and deterrents act at short range and may include both olfactory and gustatory modalities.

To test a stimulant or deterrent effect of a specific cue, oviposition cages can be used in which mosquitoes are given a choice of different oviposition substrates, and the effect of each substrate on oviposition is as sessed based on the number of eggs it receives (Millar et al. 1992, Allan and Kline 1995). On the other hand, olfactometers can be used to identify attractants and re pellents (Seenivasagan et al. 2009, 2010). Many differ ent olfactometer designs have been used in different research projects (e.g. one chamber, Y tube, T maze olfactometers). In addition, sticky screen cups to which mosquitoes could be attracted and trapped are also used in some studies to test attractants and repellents (Ponnusamy et al. 2010a,b). In semi field experiments (big field cages) or open field studies, ovitraps (oviposi tion containers) are used to measure how many eggs a certain substance (deterrent or stimulant) receives (Reiter et al. 1991, Allan and Kline 1995) while traps for gravid mosquitoes are used to test mosquito attrac tion toward an odor (attractant or repellent; McPhatter and Debboun 2009).

Different mosquito species live in a wide range of habitats and exploit different types of food (Merritt et al. 1992). Consequently, a suitable oviposition sub strate for one species could be unsuitable for another. While some oviposition cues are effective across mos quito species, others are species specific. Some attrac tant or stimulant in one species may be a repellent or deterrent in another species. Furthermore, larval expe rience could also play a role in altering the otherwise 
Table 1. Cues of plant origin and their effect on the oviposition of different mosquito species

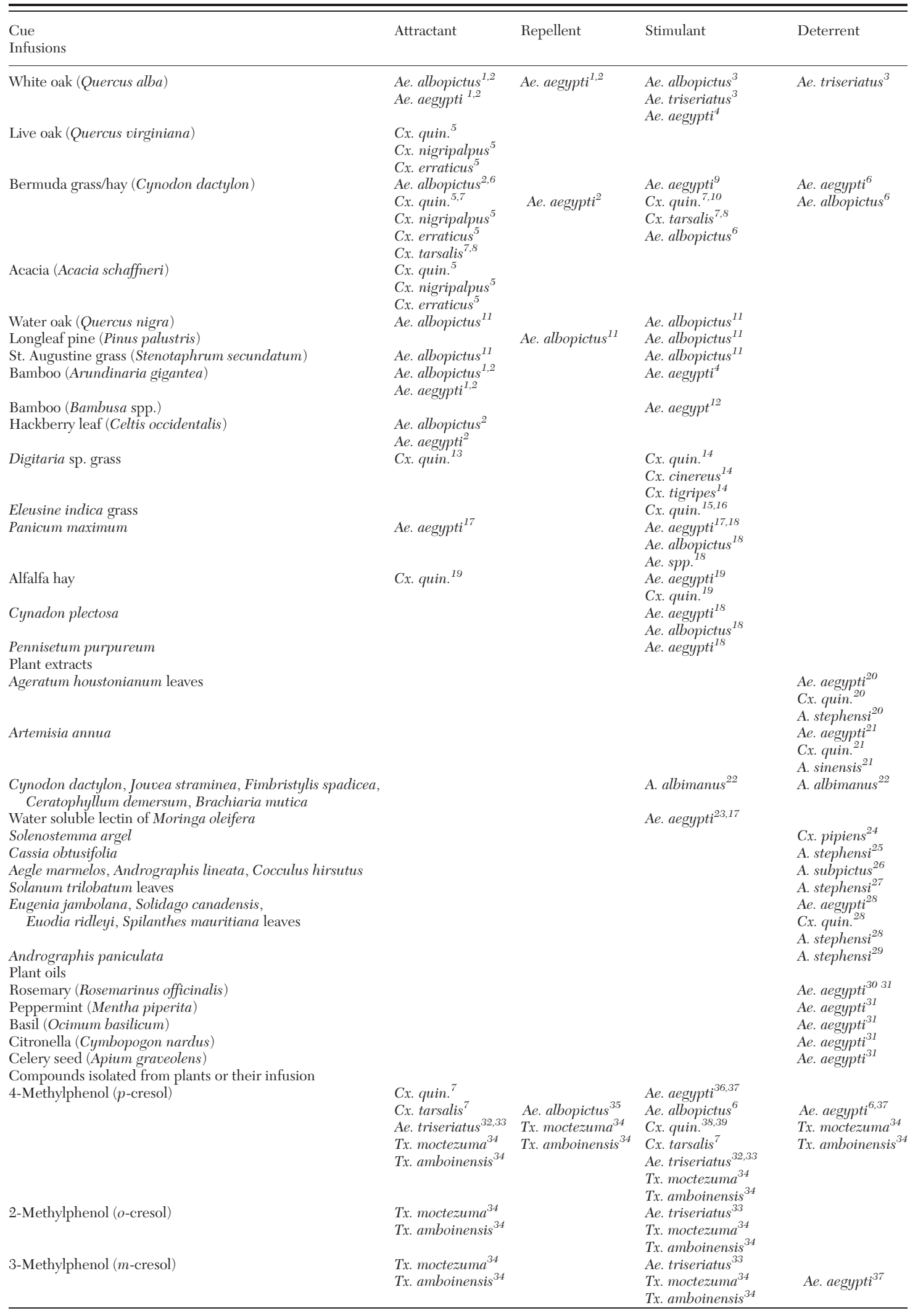


Table 1. (continued)

\begin{tabular}{|c|c|c|c|c|}
\hline $\begin{array}{l}\text { Cue } \\
\text { Infusions }\end{array}$ & Attractant & Repellent & Stimulant & Deterrent \\
\hline 2-Tridecanone & $C x$. quin. $^{7}$ & & & \\
\hline Indole & Cx. tarsalis $^{7}$ & Cx. quin. ${ }^{7}$ & $\begin{array}{l}\text { Cx. } \text { quin. }^{10} \\
\text { Cx. } \text { tarsalis }^{7}\end{array}$ & Ae. albopictus ${ }^{6}$ \\
\hline Naphthalene & & & Cx. tarsalis $^{7}$ & \\
\hline \multirow[t]{3}{*}{ 4-Methylcyclohexanol } & Ae. triseriatus $^{33}$ & & Ae. triseriatus ${ }^{33}$ & \\
\hline & Tx. moctezuma ${ }^{34}$ & & Tx. moctezuma ${ }^{34}$ & \\
\hline & Tx. amboinensis ${ }^{34}$ & & Tx. amboinensis ${ }^{34}$ & \\
\hline \multirow[t]{6}{*}{ 3-Methylindole (Skatole) } & & & Ae. albopictus ${ }^{6}$ & Ae. albopictus ${ }^{6}$ \\
\hline & Cx. quin. $^{7,38,40}$ & Cx. quin. ${ }^{7}$ & Cx. quin. $10,16,38,39,41,42$ & $\begin{array}{l}\text { Ae. aegypti } \\
\text { Cx. quin. } 41,43\end{array}$ \\
\hline & Tx. moctezuma $a^{34}$ & Tx. moctezuma $a^{34}$ & Cx. tarsalis ${ }^{7,38}$ & Tx. moctezuma $a^{34}$ \\
\hline & Tx. amboinensis ${ }^{34}$ & Tx. amboinensis ${ }^{34}$ & Cx. stig. ${ }^{38}$ & Tx. amboinensis ${ }^{34}$ \\
\hline & & & Tx. moctezuma ${ }^{34}$ & \\
\hline & & & Tx. amboinensis ${ }^{34}$ & \\
\hline Trimethylamine & Cx. quin. ${ }^{40}$ & & & \\
\hline Dimethyltrisulfide & Cx. tarsalis $^{7}$ & Cx. quin. ${ }^{7}$ & & \\
\hline Phenol & Cx. tarsalis $^{7}$ & & Ae. aegypti $i^{6,36}$ & $\begin{array}{l}\text { Ae. albopictus } \\
\text { Ae. aegypti }\end{array}$ \\
\hline 2,4-Dimethylphenol & Ae. triseriatus $^{33}$ & & Ae. triseriatus ${ }^{33}$ & \\
\hline 2,3-Dimethylphenol & & & Ae. triseriatus ${ }^{33}$ & \\
\hline \multirow[t]{2}{*}{ 4-Ethylphenol } & & & Ae. aegypti ${ }^{6}$ & Ae. albopictus ${ }^{6}$ \\
\hline & & & Ae. triseriatus ${ }^{33}$ & Ae. aegypti ${ }^{6}$ \\
\hline Camphor & & & Ae. aegypti ${ }^{30}$ & \\
\hline$\beta$-Pinene & & & Ae. aegypti $i^{30}$ & \\
\hline Borneol & & & Ae. aegypti $i^{30}$ & \\
\hline Borneol acetate & & & Ae. aegypti $i^{30}$ & \\
\hline Cineol & & & & Ae. aegypti $i^{30}$ \\
\hline Citronellal & & & & Ae. aegypti $i^{30}$ \\
\hline Eugenol & & & & Ae. aegypti $i^{30}$ \\
\hline Linalool & & & & Ae. aegyptio \\
\hline$p$-Cymene & & & & Ae. aegypti $i^{30}$ \\
\hline Pulegone & & & & Ae. aegypti $i^{30}$ \\
\hline Trans-anethole & & & & Ae. aegypti $i^{30}$ \\
\hline Thymol & & & & Ae. aegypti $i^{30}$ \\
\hline \multirow[t]{2}{*}{ Nonanal } & Cx. quin. ${ }^{7,40}$ & & Cx. tarsalis $^{7}$ & \\
\hline & Cx. tarsalis $^{7}$ & & & \\
\hline Confertifolin & & & & Ae. albopictus ${ }^{45}$ \\
\hline
\end{tabular}

Citations: ${ }^{1}$ (Ponnusamy et al. 2010a), ${ }^{2}$ (Ponnusamy et al. 2010b), ${ }^{3}$ (Trexler et al. 1998), ${ }^{4}$ (Ponnusamy et al. 2008), ${ }^{5}$ (McPhatter and Debboun Citations: ${ }^{1}$ (Ponnusamy et al. $\left.2010 \mathrm{a}\right),{ }^{2}$ (Ponnusamy et al. 2010b), ${ }^{3}$ (Trexler et al. 1998), ${ }^{4}$ (Ponnusamy et al. 2008 ), ${ }^{5}$ (McPhatter and Debboun
2009), ${ }^{6}$ (Allan and Kline 1995), ${ }^{7}$ (Du and Millar 1999), ${ }^{8}$ (Isoe et al. 1995), ${ }^{9}$ (Reiter et al. 1991), ${ }^{10}$ (Millar et al. 1992), ${ }^{11}$ (Obenauer et al. 2010), ${ }^{12}$ (Arbaoui and Chua 2014), ${ }_{13}$ (Mboera et al. 2000a), ${ }_{14}^{14}$ (Mboera et al. 1999), ${ }_{15}{ }^{15}$ (Barbosa et al. 2007), ${ }_{16}$ (Barbosa et al. 2010b), ${ }^{17}$ (Santos et al. 2014), ${ }^{18}$ (Sant'ana et al. 2006), ${ }^{19}$ (Hazard et al. 1967), ${ }^{20}$ (Tennyson et al. 2012), ${ }^{21}$ (Cheah et al. 2013), ${ }^{22}$ (Torres-Estrada et al. 2005), ${ }^{23}$ (Santos et al. 2012) ${ }^{24}$ (Al-Doghairi et al. 2004), ${ }^{25}$ (Rajkumar and Jebanesan 2009), ${ }^{26}$ (Elango et al. 2009), ${ }^{27}$ (Rajkumar and Jebanesan 2005), ${ }^{28}$ (Prathibha et al 2014), ${ }^{29}$ (Chenniappan and Kadarkarai 2008), ${ }^{30}$ (Waliwitiya et al. 2009), ${ }^{31}$ (Warikoo et al. 2011), ${ }^{32}$ (Bentley et al. 1979), ${ }^{33}$ (Bentley et al. 1981), ${ }^{34}$ (Collins and Blackwell 2002), ${ }^{35}$ (Trexler et al. 2003a), ${ }^{36}$ (Baak-Baak et al. 2013), ${ }^{37}$ (Afify and Galizia 2014), ${ }^{38}$ (Beehler et al. 1994), ${ }^{39}$ (Geetha et al. 2003), ${ }^{40}$ (Leal et al. 2008), ${ }^{41}$ (Blackwell et al. 1993), ${ }^{42}$ (Mboera et al. 2000b), ${ }^{43}$ (McCall and Eaton 2001), ${ }^{44}$ (Olagbemiro et al. 2004), ${ }^{45}$ (Maheswaran and Ignacimuthu 2014).

Ae., Aedes; Cx., Culex; Cx. quin., Culex quinquefasciatus; Cx. stig., Culex stigmatosoma; A., Anopheles; Tx., Toxorhynchites.

innate site selection behavior (McCall and Eaton 2001).

In this review, olfactory and gustatory cues that influ ence oviposition are summarized in Table 15 accord ing to their effect (stimulant or attractant, or deterrent or repellent), their source in nature, and the informa tion they provide to oviposition seeking mosquitoes. Some of these cues show concentration dependent var iability. For example, 3 methylindole is a repellent at $0.01 \mu \mathrm{g} /$ liter but an attractant at 1 and $10 \mu \mathrm{g} /$ liter for Culex quinquefasciatus Say (Du and Millar 1999). In other cases, the published data are contradictory. For example, 4 methylphenol ( $p$ cresol) has been reported as a stimulant or deterrent for Aedes aegypti L. at simi lar concentrations in different studies (Allan and Kline 1995, Baak Baak et al. 2013, Afify and Galizia 2014). These contradictions could be due to the use of differ ent testing methodologies, rearing conditions, or the presence of background odors.
We aimed at citing all studies in which the same cue was tested without judging their relative importance, and suggest referring to the original studies in order to evaluate contradictory results (the latest search for this review was done on 31 July 2014). We discussed some open questions regarding the interactions between the different cues and whether the response to these cues is innate or shaped by experience according to the available literature.

\section{Cues From Larval Food}

Plant detritus and the microorganisms that live on it in water are food sources for most mosquito larvae (Merritt et al. 1992), and affect mosquito larvae growth rates (Yee et al. 2007, Murrell and Juliano 2008, Kesavaraju et al. 2009). A number of studies have eval uated cues from plant (Table 1) and microbial (Table 2) origins on mosquito oviposition. Infusions of white oak, 
Table 2. Cues of microbial origin and their effect on the oviposition of different mosquito species

\begin{tabular}{|c|c|c|c|c|}
\hline $\begin{array}{l}\text { Cue } \\
\text { Microbes }\end{array}$ & Attractant & Repellent & Stimulant & Deterrent \\
\hline Bacteria isolated from white oak leaf infusion & & & Ae. aegypti ${ }^{1}$ & \\
\hline $\begin{array}{l}\text { Bacteria isolated from bamboo (Arundinaria gigantea) leaf } \\
\text { infusion }\end{array}$ & & & Ae. aegypti ${ }^{1}$ & \\
\hline Bacteria isolated from bamboo (Bambusa spp.) leaf infusion & & & Ae. aegypti ${ }^{2}$ & \\
\hline Bacteria isolated from alfalfa hay infusion & Cx. quin. ${ }^{3}$ & & Cx. quin. ${ }^{3}$ & \\
\hline Bacteria isolated from natural mosquito habitats & A. gambiae ${ }^{4}$ & & - & \\
\hline Bacillus sp. (from oak leaf infusion) & & & Ae. albopictus ${ }^{5}$ & \\
\hline Psychrobacter immobilis (from larval water) & & & Ae. albopictus ${ }^{5}$ & \\
\hline $\begin{array}{l}\text { Mixed cultures of bacteria from larval habitat } \\
\text { (Stenotrophomonas, Enterobacter, Pantoea, Klebsiella, } \\
\text { Acinetobacter, Aeromonas, Pseudomonas, Bacillus) }\end{array}$ & & & & A. gambiae ${ }^{6}$ \\
\hline Sphingobacterium multivorum (from soil) & & & Ae. albopictus ${ }^{5}$ & \\
\hline Culture of Bacillus sphaericus & & & Cx. quin. ${ }^{7}$ & Cx. quin. ${ }^{8}$ \\
\hline Bacillus thuringiensis var israelensis & & & $\begin{array}{l}\text { Ae. } \text { albopictus }^{9} \\
\text { Cx. quin. }\end{array}$ & Cx. quin..$^{8}$ \\
\hline Compounds from microbes & & & & \\
\hline Secondary metabolites of Trichoderma viride & & & Cx. quin. ${ }^{10}$ & \\
\hline $\begin{array}{l}\text { Compounds associated with bacteria in bamboo leaf infusion } \\
\text { (nonanoic acid, tetradecanoic acid, tetradecanoic acid } \\
\text { methyl ester) }\end{array}$ & & & Ae. aegypti ${ }^{1}$ & \\
\hline $\begin{array}{l}\text { A synthetic mixture of nonanoic acid, tetradecanoic acid, and } \\
\text { tetradecanoic acid methyl ester }\end{array}$ & & & Ae. aegypti ${ }^{1,11}$ & Ae. aegypti $i^{1}$ \\
\hline $\begin{array}{l}\text { A compound associated with bacteria in bamboo leaf infusion } \\
\text { (hexadecanoic acid methyl ester) }\end{array}$ & & & & Ae. aegypti ${ }^{1}$ \\
\hline
\end{tabular}

Citations: ${ }^{1}$ (Ponnusamy et al. 2008), ${ }^{2}$ (Arbaoui and Chua 2014), ${ }^{3}$ (Hazard et al. 1967), ${ }^{4}$ (Sumba et al. 2007), ${ }^{5}$ (Trexler et al. 2003b), ${ }^{6}$ (Huang et al. 2006), ${ }^{7}$ (Barbosa et al. 2007), ${ }^{8}$ (Zahiri and Mulla 2005), ${ }^{9}$ (Carrieri et al. 2009), ${ }^{10}$ (Geetha et al. 2003), ${ }^{11}$ (Barbosa et al. 2010a). Ae., Aedes; Cx., Culex; Cx. quin., Culex quinquefasciatus; A., Anopheles.

Bermuda grass, and bamboo (McPhatter and Debboun 2009; Obenauer et al. 2010; Ponnusamy et al. 2010a,b), or chemical compounds isolated from these infusions (3 methylindole and nonanal; Millar et al. 1992, Du and Millar 1999) were found to be stimulants and at tractants for one or more mosquito species. Microbes isolated from plant infusions (like Bacillus sp. isolated from oak leaf infusion) also stimulate and attract mos quito oviposition (Hazard et al. 1967, Trexler et al. 2003b, Ponnusamy et al. 2008). Importantly, other fac tors also influence the attractiveness of infusions, such as the mass of plant material, fermentation period (Ponnusamy et al. 2010b), and the diversity of micro bial species (Ponnusamy et al. 2010a).

Other plants (such as Solenostemma argel Delile) have a negative effect on mosquito eggs (Al Doghairi et al. 2004, Elango et al. 2009, Warikoo et al. 2011) or larvae (Al Doghairi et al. 2004, Rajkumar and Jebane san 2009). Not surprisingly, these plants were found to be deterrent for mosquito oviposition (Al Doghairi et al. 2004, Elango et al. 2009, Rajkumar and Jebane san 2009, Warikoo et al. 2011), showing that mosqui toes avoid conditions that are noxious to their offspring. However, suitability for the offspring does not always explain the oviposition effect of plant infusions; the water soluble lectin isolated from the Moringa oleifera Lamarck tree is larvicidal and ovicidal against Ae. aegypti (Coelho et al. 2009, Santos et al. 2012), but stimulates oviposition in this species (Santos et al. 2012). No explanation for this counterintuitive effect is as yet known.

Some oviposition responses are experience depen dent. $C x$. quinquefasciatus larvae reared in water containing an innately deterrent concentration of 3 methylindole subsequently preferred water contain ing the same concentration of 3 methylindole over the normally attractive $p$ cresol (McCall and Eaton 2001). Learning that is transferred through metamorphosis (McCall and Eaton 2001) may be insufficient, and ad ditional enforcement at the early adult stage may be necessary (Hamilton et al. 2011).

\section{Cues From Mosquito Immature Stages}

The current or previous presence of a low density of other mosquitoes in the water (i.e. eggs, larvae, and pu pae) could encourage conspecific mosquitoes to use the same site (Soman and Reuben 1970, Trimble and Wellington 1980, Wachira et al. 2010, Wong et al. 2011). Pheromones from immature stages that stimu late their conspecifics to lay eggs have been identified (Mboera et al. 2000a,b; Mendki et al. 2000; Ganesan et al. 2006; Seenivasagan et al. 2009). However, high densities of mosquito immature stages in water gener ate competition, with negative effects on larvae and the emerging adults (Ho et al. 1989, Reiskind and Louni bos 2009). Indeed, water that contains high numbers of immature stages (Zahiri and Rau 1998) or high dose of their pheromones (Barbosa et al. 2007, Seenivasagan et al. 2009) is deterrent and repellent for the oviposi tion of their conspecifics. This means that mosquitoes evaluate not only the presence of conspecifics but also their density. Similarly, water that contains starved lar vae (Zahiri and Rau 1998) or larvae that are infected with pathogens (Zahiri and Rau 1998, Zettel Nalen et al. 2013) also deter egg laying of conspecifics, 
Table 3. Cues of mosquito immature stages and their effect on the oviposition of different mosquito species

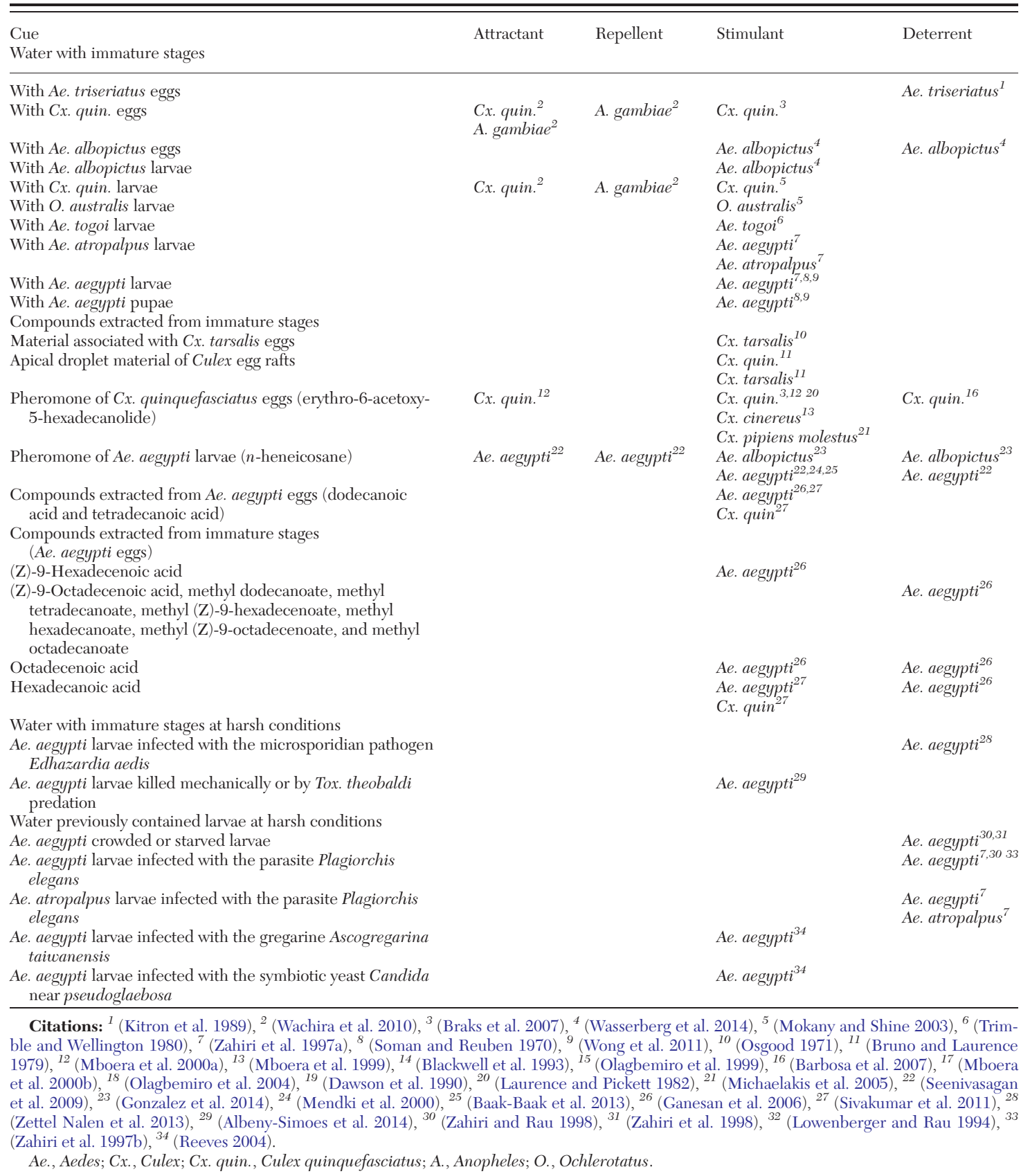

suggesting that other compounds could be released from unhealthy larvae and inhibit oviposition of their conspecific gravid females.

Cues of mosquito immature stages could also affect oviposition of nonconspecific gravid females; Anopheles gambiae Giles gravid females prefer water with low density of $C x$. quinquefasciatus eggs, and avoid water with high density of $C x$. quinquefasciatus eggs or any densities of $C x$. quinquefasciatus larvae (Wachira et al. 2010). The pheromone released by $C x$. quinquefasciatus eggs stimulates egg laying of Culex cinereus Theobald (Mboera et al. 1999) and Culex pipiens L. (Michaelakis et al. 2005), suggesting a general oviposition stimulant effect on Culex mosquitoes.

In nature, cues of most mosquito immature stages are not present in clean water but rather in water that contains other cues (e.g. plant detritus), and these signals may interact. Indeed, a mixture of erythro 6 acetoxy 5 hexadecanolide (a pheromone of $C x$. quinquefasciatus eggs) with grass infusion 
Table 4. Cues of mosquito predators and their effect on the oviposition of different mosquito species

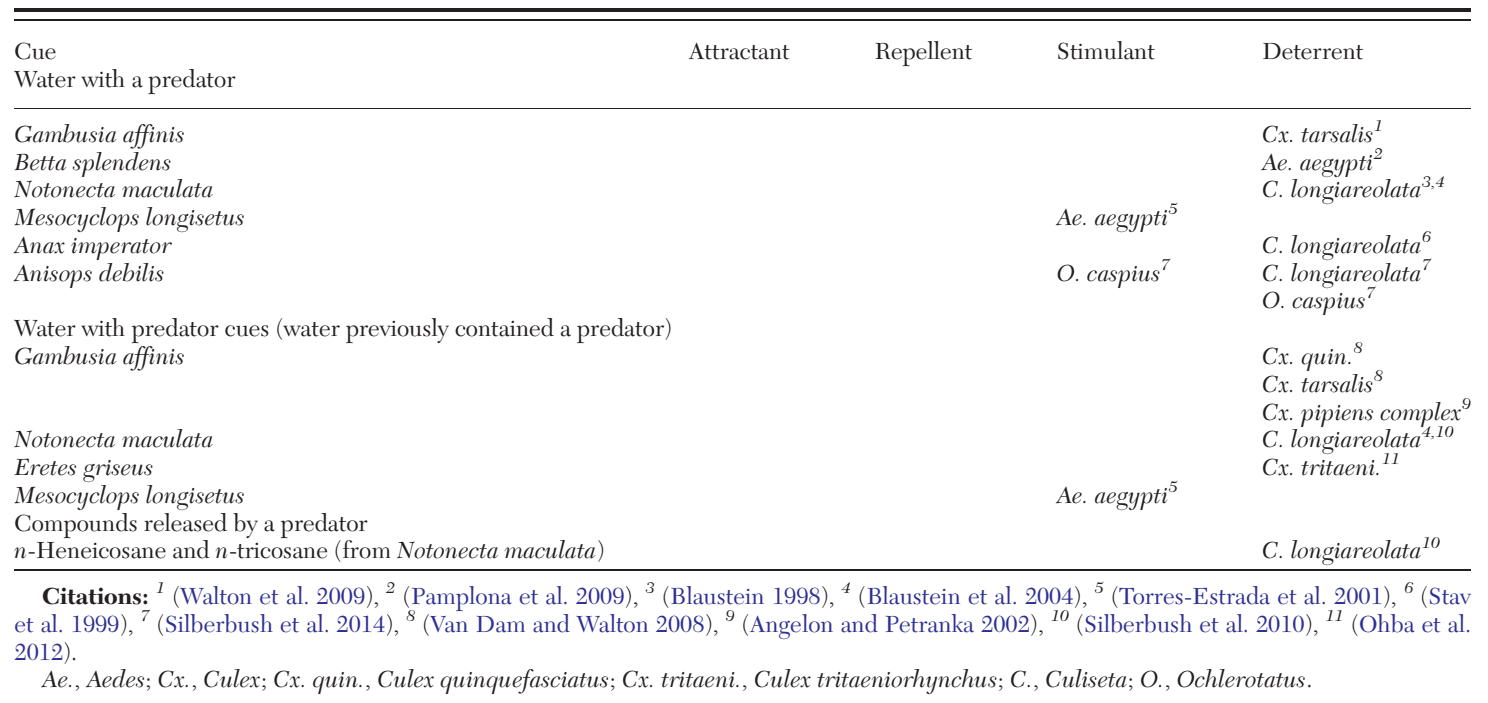

encouraged oviposition more than the pheromone or the infusion alone (Mboera et al. 1999). A synergistic effect was also shown for this pheromone with the plant derived oviposition attractant 3 methylindole (Olagbemiro et al. 2004).

\section{Cues From Mosquito Predators}

Predators in water reduce mosquito larval populations (Blaustein 1998, Pyke 2005). Intuitively, gravid females may avoid laying eggs on water that contains predator cues (Table 4). Indeed, cues from the mosquito fish Gambusia affinis Gaird \& Girard (Angelon and Pet ranka 2002, Van Dam and Walton 2008), the dragonfly predator Anax imperator Leach (Stav et al. 1999), and the hemipteran predator Notonecta maculata Fabricius (Blaustein et al. 2004) were found deterrent for mos quito oviposition. Furthermore, two compounds ( $n$ heneicosane and $n$ tricosane) released by $N$. maculata induce oviposition avoidance in Culiseta longiareolata Macquart (Silberbush et al. 2010).

Responses toward predator cues are species specific. They may be partly genetically encoded and partly experience dependent. Cx. quinquefasciatus and $C x$. tarsalis experience high predation by $G$. affinis in nature and avoid laying eggs in containers with preda tor cues, while Ae. aegypti has low risk of predation by G. affinis in nature and shows no oviposition avoidance behavior (Van Dam and Walton 2008). Similarly, the wetland mosquito Culex tritaeniorhynchus Giles avoids cues of the predacious beetle Eretes griseus Fabricius, while Aedes albopictus Skuse, which do not share the same habitat, are not affected by these cues (Ohba et al. 2012). An interesting case is given by $n$ heneico sane, the component released by N. maculata and re sponsible for its oviposition deterrent effect on $C$. longiareolata (Silberbush et al. 2010). For Ae. aegypti mosquitoes, this substance is an oviposition pheromone released from larval cuticle, and accordingly not deterrent (Mendki et al. 2000, Seenivasagan et al 2009). The $n$ heneicosane is released by Ae. aegypti lar vae which live in small containers. This is a very differ ent habitat with different predation exposure than the pool environment inhabited by N. maculata (Silberbush et al. 2010). Mosquito species with no evolutionary experience with a predator have not evolved avoid ance of water containing that predator or its chemical cues.

In an evolutionary arms race, the presence of a natu ral predator or its chemical cues could be undetectable or even attractant to its prey mosquitoes; the presence of the backswimmer predator Anisops wakefieldi White or its chemical cues had no effect on the oviposition of the prey mosquito Culex pervigilans Pergorth (Zuharah and Lester 2010). Interestingly, Ae. aegypti prefers to lay eggs in containers with its predacious co pepod Mesocyclops longisetus Thiébaud or in con tainers that had M. longisetus for 48 hours, in a choice against clean water (Torres Estrada et al. 2001). $M$. longisetus is a voracious natural predator of $A e$. aegypti larvae (Marten et al. 1994). It is not known why Ae. aegypti is attracted rather than repelled by its cope pod predator.

Unlike the synergistic effects of plant derived sub stances and pheromones (see above), no interaction has been reported yet between food supply and predator presence. Oviposition of Ae. albopictus decreased with the presence of predator dragonfly nymphs and in creased with the increase of food levels, but these ef fects were independent from each other (Wasserberg et al. 2013).

\section{Synthetic Compounds}

Several studies addressed the possibility of using syn thetic compounds to influence mosquito oviposition (Table 5). Some of these compounds were first isolated and identified from plant infusions, bacterial cultures, 
Table 5. Synthetic compounds and their effect on the oviposition of different mosquito species

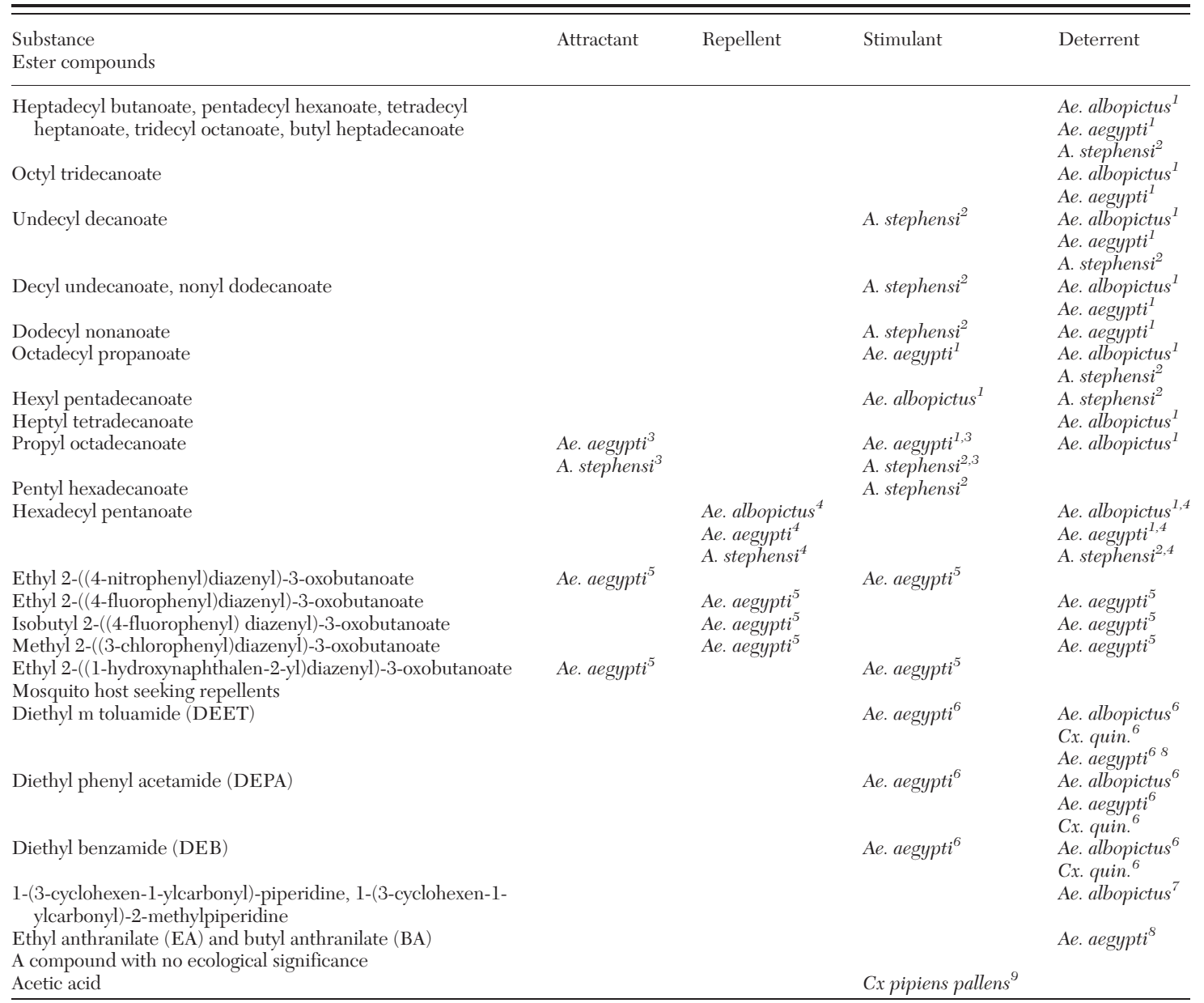

Citations: ${ }^{1}$ (Sharma et al. 2008), ${ }^{2}$ (Sharma et al. 2009), ${ }^{3}$ (Seenivasagan et al. 2012), ${ }^{4}$ (Seenivasagan et al. 2010), ${ }^{5}$ (Guha et al. 2012), ${ }^{6}$ (Tikar et al. 2014), ${ }^{7}$ (Xue et al. 2001), ${ }^{8}$ (Afify et al. 2014), ${ }^{9}$ (Li et al. 2009).

Ae., Aedes; Cx., Culex; Cx. quin., Culex quinquefasciatus; A., Anopheles.

or mosquito immature stages (included in Tables 1,2 or 3 for convenience). Ester compounds are abundant in dipteran sex pheromones (Jacobson et al. 1973), and also received an interest as potential oviposition cues. Some ester compounds were found to stimulate/attract mosquito oviposition while others were oviposition de terrents/repellents (Sharma et al. 2008, 2009; Seeniva sagan et al. 2010, 2012; Guha et al. 2012). Synthetic compounds may resemble natural compounds that are present in the animal's ecological environment, but for some (including some known repellents that affect host seeking), no ecological significance is known ( $\mathrm{Li}$ et al. 2009, Tikar et al. 2014).

\section{Conclusion}

In this review, we collect available information about substances that either increase or decrease oviposition in different species. The data are reported in Tables 15 , and sorted by origin of the substances studied. What is apparent in the tables is that our knowledge is quite partial indeed: some species are well studied for many substances, and some substances for many species. But in most cases, knowledge is partial. It is important to emphasize these shortcomings, because the data also show that the same substance can have very different effect depending on the experimental conditions and on the species used. We hope that our collection will be of use to the community in designing future experiment to study mosquito behavior, and to design suitable approaches for environmentally friendly mosquito con trol strategies.

\section{Acknowledgments}

We would like to thank the International Max Planck Research School (IMPRS) for Organismal Biology, the German Research Foundation (DFG), and the University of Konstanz for funding this study. 


\section{References Cited}

Afify, A., and C. G. Galizia. 2014. Gravid females of the mosquito Aedes aegypti avoid oviposition on $m$-cresol in the presence of the deterrent isomer $p$-cresol. Parasit. Vectors 7: 315 .

Afify, A., B. Horlacher, J. Roller, and C. G. Galizia. 2014. Different repellents for Aedes aegypti against blood-feeding and oviposition. PLoS ONE 9: e103765.

Al-Doghairi, M., A. El-Nadi, E. Elhag, and H. Al-Ayedh. 2004. Effect of Solenostemma argel on oviposition, egg hatchability and viability of Culex pipiens $\mathrm{L}$. larvae. Phytother. Res. 18: 335 338.

Albeny-Simões, D., E. G. Murrell, S. L. Elliot, M. R. Andrade, E. Lima, S. A. Juliano, and E. F. Vilela. 2014 Attracted to the enemy: Aedes aegypti prefers oviposition sites with predator-killed conspecifics. Oecologia 175: 481492.

Allan, S. A., and D. L. Kline. 1995. Evaluation of organic infusions and synthetic compounds mediating oviposition in Aedes albopictus and Aedes aegypti (Diptera: Culicidae). J. Chem. Ecol. 21: 18471860.

Angelon, K. A., and J. W. Petranka. 2002. Chemicals of predatory mosquitofish (Gambusia affinis) influence selection of oviposition site by Culex mosquitoes. J. Chem. Ecol. 28: 797806.

Arbaoui, A. A., and T. H. Chua. 2014. Bacteria as a source of oviposition attractant for Aedes aegypti mosquitoes. Trop. Biomed. 31: 134142.

Baak-Baak, C. M., A. D. Rodríguez-Ramirez, J. E. GarcíaRejón, S. Ríos-Delgado, and J. L. Torres-Estrada. 2013. Development and laboratory evaluation of chemically-based baited ovitrap for the Monitoring of Aedes aegypti. J. Vector Ecol. 38: 175 181.

Barbosa, R. M., A. Souto, A. E. Eiras, and L. Regis. 2007. Laboratory and field evaluation of an oviposition trap for Culex quinquefasciatus (Diptera: Culicidae). Mem. Inst Oswaldo Cruz 102: 523529.

Barbosa, R. M., A. Furtado, L. Regis, and W. S. Leal. 2010a. Evaluation of an oviposition-stimulating kairomone for the yellow fever mosquito, Aedes aegypti, in Recife, Brazil. J. Vector Ecol. 35: 204207.

Barbosa, R. M., L. Regis, R. Vasconcelos, and W. S. Leal. 2010b. Culex mosquitoes (Diptera: Culicidae) egg laving in traps loaded with Bacillus thuringiensis variety israelensis and baited with skatole. J. Med. Entomol. 47:345 348.

Beehler, J. W., J. G. Millar, and M. S. Mulla. 1994. Field evaluation of synthetic compounds mediating oviposition in Culex mosquitoes (Diptera: Culicidae). J. Chem. Ecol. 20 281291.

Bentley, M. D., and J. F. Day. 1989. Chemical ecology and behavioral aspects of mosquito oviposition. Annu. Rev. Entomol. 34: 401421.

Bentley, M. D., I. N. McDaniel, M. Yatagai, H. P. Lee, and R. Maynard. 1979. $p$-Cresol: an oviposition attractant of Aedes triseriatus. Environ. Entomol. 8: 206209.

Bentley, M. D., I. N. McDaniel, M. Yatagai, H. Lee, and R. Maynard. 1981. Oviposition attractants and stimulunts of Aedes triseriatus (Say) (Diptera:Culicidae). Environ. Entomol. 10: 186189

Blackwell, A., A. J. Mordue (Luntz), B. S. Hansson, L. J. Wadhams, and J. A. Pickett. 1993. A behavioural and electrophysiological study of oviposition cues for Culex quinquefasciatus. Physiol. Entomol. 18: 343348.

Blaustein, L. 1998. Influence of the predatory backswimmer, Notonecta maculata, on invertebrate community structure. Ecol. Entomol. 23: 246252.

Blaustein, L., M. Kiflawi, A. Eitam, M. Mangel, and J. Cohen. 2004. Oviposition habitat selection in response to risk of predation in temporary pools: mode of detection and consistency across experimental venue. Oecologia 138: 300305.

Braks, M.A.H., W. S. Leal, and R. T. Cardé. 2007. Oviposition responses of gravid female Culex quinquefasciatus to ego rafts and low doses of oviposition pheromone under semifield conditions. J. Chem. Ecol. 33: 567578.

Bruno, D. W., and B. R. Laurence. 1979. The influence of the apical droplet of Culex Egg rafts on oviposition of Culex pipiens fatigans (Diptera: Culicidae). J. Med. Entomol. 16: 300305.

Carrieri, M., A. Masetti, A. Albieri, B. Maccagnani, and R. Bellini. 2009. Larvicidal activity and influence of Bacillus thuringiensis var. israelensis on Aedes albopictus oviposition in ovitraps during a two-week check interval protocol. J. Am. Mosq. Control Assoc. 25: 149155.

Cheah, S.-X., J.-W. Tay, L.-K. Chan, and Z. Jaal. 2013. Larvicidal, oviposition, and ovicidal effects of Artemisia annua (Asterales: Asteraceae) against Aedes aegypti, Anopheles sinensis, and Culex quinquefasciatus (Diptera: Culicidae). Parasitol. Res. 112: 32753282.

Chenniappan, K., and M. Kadarkarai. 2008. Oviposition deterrent, ovicidal and gravid mortality effects of ethanolic extract of Andrographis paniculata Nees against the malarial vector Anopheles stephensi Liston (Diptera: Culicidae). Entomol. Res. 38: 119 125.

Clements, A. N. 1999. The biology of mosquitoes. Sensory reception and behaviour, vol. 2. CABI Publishing, Wallingford, United Kingdom.

Coelho, J. S., N.D.L. Santos, T. H. Napoleão, F. S. Gomes, R. S. Ferreira, R. B. Zingali, L.C.B.B. Coelho, S. P. Leite, D.M.A.F. Navarro, and P.M.G. Paiva. 2009. Effect of Moringa oleifera lectin on development and mortality of Aedes aegypti larvae. Chemosphere 77: 934938.

Collins, L. E., and A. Blackwell. 2002. Olfactory cues for oviposition behavior in Toxorhynchites moctezuma and Toxorhynchites amboinensis (Diptera: Culicidae). J. Med. Entomol. 39: 121126.

Dawson, G. W., A. Mudd, J. A. Pickett, M. M. Pile, and L. J. Wadhams. 1990. Convenient synthesis of mosquito oviposition pheromone and a highly fluorinated analog retaining biological activity. J. Chem. Ecol. 16: 17791789.

Du, Y. J., and J. G. Millar. 1999. Electroantennogram and oviposition bioassay responses of Culex quinquefasciatus and Culex tarsalis (Diptera: Culicidae) to chemicals in odors from Bermuda grass infusions. J. Med. Entomol. 36: 158166.

Elango, G., A. Bagavan, C. Kamaraj, A. Abduz Zahir, and A. Abdul Rahuman. 2009. Oviposition-deterrent, ovicidal, and repellent activities of indigenous plant extracts against Anopheles subpictus Grassi (Diptera: Culicidae). Parasitol. Res. 105: 15671576.

Ganesan, K., M. J. Mendki, M.V.S. Suryanarayana, S. Prakash, and R. C. Malhotra. 2006. Studies of Aedes aegypti (Diptera: Culicidae) ovipositional responses to newly identified semiochemicals from conspecific eggs. Aust. J. Entomol. 45: 7580 .

Geetha, I., K. P. Paily, V. Padmanaban, and K. Balaraman. 2003. Oviposition response of the mosquito, Culex quinquefasciatus to the secondary metabolite(s) of the fungus, Trichoderma viride. Mem. Inst. Oswaldo Cruz 98: 223226 .

Gonzalez, P. V., P.A.G. Audino, and H. M. Masuh. 2014. Electrophysiological and behavioural response of Aedes albopictus to $n$-heinecosane, an ovipositional pheromone of Aedes aegypti. Entomol. Exp. Appl. 151: 191197.

Guha, L., T. Seenivasagan, P. Bandyopadhyay, S. T. Iqbal, M. Sathe, P. Sharma, B. D. Parashar, and M. P. 
Kaushik. 2012. Oviposition and flight orientation response of Aedes aegypti to certain aromatic aryl hydrazono esters. Parasitol. Res. 111: 975982.

Hamilton, C. E., D. V. Beresford, and J. F. Sutcliffe. 2011. Effects of natal habitat odour, reinforced by adult experience, on choice of oviposition site in the mosquito Aedes aegypti. Med. Vet. Entomol. 25: 428435.

Hazard, E. I., M. S. Mayer, and K. E. Savaoe. 1967. Attraction and oviposition stimulation of gravid female mosquitoes by bacteria from hay infusion. Mosq. News 27: 133136.

Ho, B., A. Ewert, and L. Chew. 1989. Interspecific competition among Aedes aegypti, Ae. albopictus, and Ae.triseriatus (Diptera: Culicidae): larval development in mixed cultures. J. Med. Entomol. 26: 615623.

Huang, J., J. R. Miller, S. Chen, J. M. Vulule, and E. D. Walker. 2006. Anopheles gambiae (Diptera: Culicidae) oviposition in response to agarose media and cultured bacterial volatiles. J. Med. Entomol. 43: 498504.

Isoe, J., J. G. Millar, and J. W. Beehler. 1995. Bioassays for Culex (Diptera: Culicidae) mosquito oviposition attractants and stimulants. J. Med. Entomol. 32: 475483.

Jacobson, M., K. Ohinata, D. L. Chambers, W. A. Jones, and M. S. Fujimoto. 1973. Insect sex attractants. 13 Isolation, identification, and synthesis of sex pheromones of the male Mediterranean fruit fly. J. Med. Chem. 16: 246251.

Kesavaraju, B., A. Afify, and R. Gaugler. 2009. Growth and survival of the invasive Aedes albopictus larvae on Diospyros virginiana (American persimmon) leaves. J. Med. Entomol. 46: 465470

Kitron, U. D., D. W. Webb, and R. J. Novak. 1989. Oviposition behavior of Aedes triseriatus (Diptera: Culicidae): prevalence, intensity, and aggregation of eggs in oviposition traps. J. Med. Entomol. 26: 462467.

Laurence, B. R., and J. A. Pickett. 1982. Erythro-6-acetxoy-5-hexadecanolide, the major component of a mosquito oviposition attractant pheromone. J. Chem. Soc. Chem. Commun. 1982: 5960 .

Leal, W. S., R.M.R. Barbosa, W. Xu, Y. Ishida, Z. Syed, N. Latte, A. M. Chen, T. I. Morgan, A. J. Cornel, and A. Furtado. 2008. Reverse and conventional chemical ecology approaches for the development of oviposition attractants for Culex mosquitoes. PLoS ONE 3: e3045.

Li, J., T. Deng, H. Li, L. Chen, and J. Mo. 2009. Effects of water color and chemical compounds on the oviposition behavior of gravid Culex pipiens pallens females under laboratory conditions. J. Agric. Urban Entomol. 26: 2330.

Lowenberger, C. A., and M. E. Rau. 1994. Selective oviposition by Aedes aegypti (Diptera: Culicidae) in response to a larval parasite, Plagiorchis elegans (Trematoda: Plagiorchiidae). Environ. Entomol. 23: 12691276.

Maheswaran, R., and S. Ignacimuthu. 2014. Effect of Polygonum hydropiper $\mathrm{L}$. against dengue vector mosquito Aedes albopictus L. Parasitol. Res.: 18.

Marten, G. G., G. Borjas, M. Cush, E. Fernandez, and J. Reid. 1994. Control of larval Aedes aegypti (Diptera: Culicidae) by cyclopoid copepods in peridomestic breeding containers. J. Med. Entomol. 31: 3644.

Mboera, L.E.G., W. Takken, K. Y. Mdira, and J. A. Pickett. 2000a. Sampling gravid Culex quinquefasciatus (Diptera: Culicidae) in Tanzania with traps baited with synthetic oviposition pheromone and grass infusions. J. Med. Entomol. 37: 172176.

Mboera, L.E.G., K. Y. Mdira, F. M. Salum, W. Takken, and J. A. Pickett. 1999. Influence of synthetic oviposition pheromone and volatiles from soakage pits and grass infusions upon oviposition site-selection of Culex mosquitoes in Tanzania. J. Chem. Ecol. 25: 18551865.
Mboera, L.E.G., W. Takken, K. Y. Mdira, G. J. Chuwa, and J. A. Pickett. 2000b. Oviposition and behavioral responses of Culex quinquefasciatus to Skatole and synthetic oviposition pheromone in Tanzania. J. Chem. Ecol. 26: 11931203.

McCall, P. J., and G. Eaton. 2001. Olfactory memory in the mosquito Culex quinquefasciatus. Med. Vet. Entomol. 15: 197203.

McPhatter, L. P., and M. Debboun. 2009. Attractiveness of botanical infusions to ovipositing Culex quinquefasciatus, $C x$. nigripalpus, and Cx. erraticus in San Antonio, Texas. J. Am. Mosq. Control Assoc. 25: 508510

Mendki, M. J., K. Ganesan, S. Prakash, M. V. S. Suryanarayana, R. C. Malhotra, K. M. Rao, and R. Vaidyanathaswamy. 2000. Heneicosane: an oviposition-attractant pheromone of larval origin in Aedes aegypti mosquito. Curr. Sci. 78: 12951296

Merritt, R. W., R. H. Dadd, and E. D. Walker. 1992. Feeding behavior, natural food, and natural relationships of larval mosquitoes. Annu. Rev. Entomol. 37: 349376

Michaelakis, A., A. P. Mihou, E. A. Couladouros, A. K. Zounos, and G. Koliopoulos. 2005. Oviposition responses of Culex pipiens to a synthetic racemic Culex quinquefasciatus oviposition aggregation pheromone. J. Agric. Food Chem. 53: 52255229.

Millar, J. G., J. D. Chaney, and M. S. Mulla. 1992. Identification of oviposition attractants for Culex quinquefasciatus from fermented Bermuda grass infusions. J. Am. Mosq. Control Assoc. 8: 1117 .

Mokany, A., and R. Shine. 2003. Oviposition site selection by mosquitoes is affected by cues from conspecific larvae and anuran tadpoles. Austral Ecol. 28: 3337.

Murrell, E. G., and S. A. Juliano. 2008. Detritus type alters the outcome of interspecific competition between Aedes aegypti and Aedes albopictus (Diptera: Culicidae). J. Med. Entomol. 45: 375383.

Obenauer, P. J., S. A. Allan, and P. E. Kaufman. 2010. Aedes albopictus (Diptera: Culicidae) oviposition response to organic infusions from common flora of suburban Florida. J. Vector Ecol. 35: 301306.

Ohba, S.-Y., M. Ohtsuka, T. Sunahara, Y. Sonoda, E. Kawashima, and M. Takagi. 2012. Differential responses to predator cues between two mosquito species breeding in different habitats. Ecol. Entomol. 37: 410418.

Olagbemiro, T. O., M. A. Birkett, A. J. Mordue (Luntz), and J. A. Pickett. 1999. Production of (5R,6S)6-acetoxy-5-hexadecanolide, the mosquito oviposition pheromone, from the seed oil of the summer cypress plant, Kochia scoparia (Chenopodiaceae). J. Agric. Food Chem. 47: 34113415.

Olagbemiro, T. O., M. A. Birkett, A. J. Mordue, and J. A. Pickett. 2004. Laboratory and field responses of the mosquito, Culex quinquefasciatus, to plant-derived Culex spp. oviposition pheromone and the oviposition cue skatole. J. Chem. Ecol. 30: 965976.

Osgood, C. E. 1971. An oviposition pheromone associated with the egg-rafts of Culex tarsalis. J. Econ. Entomol. 64: 10381041

Pamplona, L.G.C., C. H. Alencar, J. W. O. Lima, and J. Heukelbach. 2009. Reduced oviposition of Aedes aegypti gravid females in domestic containers with predatory fish. Trop. Med. Int. Health 14: 13471350.

Ponnusamy, L., D. M. Wesson, C. Arellano, C. Schal, and C. S. Apperson. 2010a. Species composition of bacterial communities influences attraction of mosquitoes to experimental plant infusions. Microb. Ecol. 59: 158173.

Ponnusamy, L., N. Xu, S. Nojima, D. M. Wesson, C. Schal, and C. S. Apperson. 2008. Identification of bacteria and bacteria-associated chemical cues that mediate oviposition 
site preferences by Aedes aegypti. Proc. Natl. Acad. Sci. USA 105: 92629267

Ponnusamy, L., N. Xu, K. Böröczky, D. M. Wesson, L. Abu Ayyash, C. Schal, and C. S. Apperson. 2010b. Oviposition responses of the mosquitoes Aedes aegypti and Aedes albopictus to experimental plant infusions in laboratory bioassays. J. Chem. Ecol. 36: 709719 .

Prathibha, K. P., B. S. Raghavendra, and V. A. Vijayan. 2014. Larvicidal, ovicidal, and oviposition-deterrent activities of four plant extracts against three mosquito species. Environ. Sci. Pollut. Res. 21: 67366743

Pyke, G. H. 2005. A review of the biology of Gambusia affinis and G. holbrooki. Rev. Fish Biol. Fish. 15: 339365.

Rajkumar, S., and A. Jebanesan. 2005. Oviposition deterrent and skin repellent activities of Solanum trilobatum leaf extract against the malarial vector Anopheles stephensi. J. Insect Sci. 5: 15 .

Rajkumar, S., and A. Jebanesan. 2009. Larvicidal and oviposition activity of Cassia obtusifolia Linn (Family: Leguminosae) leaf extract against malarial vector, Anopheles stephensi Liston (Diptera: Culicidae). Parasitol. Res. 104: 337340.

Reeves, W. K. 2004. Oviposition by Aedes aegypti (Diptera: Culicidae) in relation to conspecific larvae infected with internal symbiotes. J. Vector Ecol. 29: 159163.

Reiskind, M. H., and L. P. Lounibos. 2009. Effects of intraspecific larval competition on adult longevity in the mosquitoes Aedes aegypti and Aedes albopictus. Med. Vet. Entomol. 23: 6268 .

Reiter, P., M. A. Amador, and N. Colon. 1991. Enhancement of the CDC ovitrap with hay infusion for daily monitoring of Aedes aegypti populations. J. Am. Mosq. Control Assoc. 7: 5255 .

Sant'ana, A. L., R. A. Roque, and A. E. Eiras. 2006. Characteristics of grass infusions as oviposition attractants to Aedes (Stegomyia) (Diptera: Culicidae). J. Med. Entomol. 43 214220

Santos, N.D.L., K. S. de Moura, T. H. Napoleão, G.K.N. Santos, L.C.B.B. Coelho, D.M.A.F. Navarro, and P. M. G. Paiva. 2012. Oviposition-stimulant and ovicidal activities of Moringa oleifera lectin on Aedes aegypti. PLoS ONE 7 e44840.

Santos, N.D.L., K. S. Paixao, T. H. Napoleao, P. B. Trindade, M. R. Pinto, L. C. Coelho, A. E. Eiras, D. M. Navarro, and P. M. Paiva. 2014. Evaluation of Moringa oleifera seed lectin in traps for the capture of Aedes aegypti eggs and adults under semi-field conditions. Parasitol. Res. 113 18371842.

Seenivasagan, T., K. R. Sharma, and S. Prakash. 2012. Electroantennogram, flight orientation and oviposition responses of Anopheles stephensi and Aedes aegypti to a fatty acid esterpropyl octadecanoate. Acta Trop. 124: 5461.

Seenivasagan, T., K. R. Sharma, K. Ganesan, and S. Prakash. 2010. Electrophysiological, flight orientation and oviposition responses of three species of mosquito vectors to Hexadecyl Pentanoate: residual oviposition repellent activity. J. Med. Entomol. 47:329 337.

Seenivasagan, T., K. R. Sharma, K. Sekhar, K. Ganesan, S. Prakash, and R. Vijayaraghavan. 2009. Electroantennogram, flight orientation, and oviposition responses of Aedes aegypti to the oviposition pheromone $n$-heneicosane. Parasitol. Res. 104: 827 833.

Sharma, K. R., T. Seenivasagan, A. N. Rao, K. Ganesan, O. P. Agarwal, and S. Prakash. 2009. Mediation of oviposition responses in the malaria mosquito Anopheles stephensi Liston by certain fatty acid esters. Parasitol. Res. 104: 281286.

Sharma, K. R., T. Seenivasagan, A. N. Rao, K. Ganesan, O. P. Agarwal, R. C. Malhotra, and S. Prakash. 2008
Oviposition responses of Aedes aegypti and Aedes albopictus to certain fatty acid esters. Parasitol. Res. 103: 10651073.

Silberbush, A., I. Tsurim, Y. Margalith, and L. Blaustein. 2014. Interactive effects of salinity and a predator on mosquito oviposition and larval performance. Oecologia 175: 565575 .

Silberbush, A., S. Markman, E. Lewinsohn, E. Bar, J. E. Cohen, and L. Blaustein. 2010. Predator-released hydrocarbons repel oviposition by a mosquito. Ecol. Lett. 13: 11291138.

Sivakumar, R., A. Jebanesan, M. Govindarajan, and P. Rajasekar. 2011. Oviposition attractancy of dodecanoic, hexadecanoic and tetradecanoic acids against Aedes aegypti and Culex quinquefasciatus (Diptera: Culicidae). Eur. Rev. Med. Pharmacol. Sci. 15: 11721175.

Soman, R. S., and R. Reuben. 1970. Studies on the preference shown by ovipositing females of Aedes aegypti for water containing immature stages of the same species. J. Med. Entomol. 7: 485489 .

Stav, G., L. Blaustein, and J. Margalith. 1999. Experimental evidence for predation risk sensitive oviposition by a mosquito, Culiseta longiareolata. Ecol. Entomol. 24: 202207.

Sumba, L. A., T. O. Guda, A. L. Deng, A. Hassanali, J. C. Beier, and B.G.J. Knols. 2007. Mediation of oviposition site selection in the African malaria mosquito Anopheles gambiae (Diptera: Culicidae) by semiochemicals of microbial origin. Int. J. Trop. Insect Sci. 24.

Tennyson, S., K. J. Ravindran, A. Eapen, and S. J. William. 2012. Effect of Ageratum houstoniamum Mill. (Asteraceae) leaf extracts on the oviposition activity of Anopheles stephensi, Aedes aegypti and Culex quinquefasciatus (Diptera: Culicidae). Parasitol. Res. 111: 22952299.

Tikar, S. N., R. Yadav, M. J. Mendki, A. N. Rao, D. Sukumaran, and B. D. Parashar. 2014. Oviposition deterrent activity of three mosquito repellents diethyl phenyl acetamide (DEPA), diethyl $\mathrm{m}$ toluamide (DEET), and diethyl benzamide (DEB) on Aedes aegypti, Aedes albopictus, and Culex quinquefasciatus. Parasitol. Res. 113: 101106

Torres-Estrada, J. L., M. H. Rodriguez, L. Cruz-Lopez, and J. I. Arredondo-Jimenez. 2001. Selective oviposition by Aedes aegypti (Diptera: culicidae) in response to Mesocyclops longisetus (Copepoda: Cyclopoidea) under laboratory and field conditions. J. Med. Entomol. 38: 188192.

Torres-Estrada, J. S., R. A. Meza-Alvarez, J. Cibrían-Tovar, M. H. Rodríguez-López, J. I. Arredondo-Jiménez, L. Cruz-López, and J. C. Rojas-Leon. 2005. Vegetation-derived cues for the selection of oviposition substrates by Anopheles albimanus under laboratory conditions. J. Am. Mosq. Control Assoc. 21:344 349 .

Trexler, J. D., C. S. Apperson, and C. Schal. 1998. Laboratory and field evaluations of oviposition responses of Aedes albopictus and Aedes triseriatus (Diptera: Culicidae) to oak leaf infusions. J. Med. Entomol. 35: 967976.

Trexler, J. D., C. S. Apperson, C. Gemeno, M. J. Perich, D. Carlson, and C. Schal. 2003a. Field and laboratory evaluations of potential oviposition attractants for Aedes albopictus (Diptera: Culicidae). J. Am. Mosq. Control Assoc. 19: 228234

Trexler, J. D., C. S. Apperson, L. Zurek, C. Gemeno, C. M. Kaufman, E. Walker, D. W. Watson, and L. Wallace. 2003b. Role of bacteria in mediating the oviposition responses of Aedes albopictus (Diptera: Culicidae). J. Med. Entomol. 40: 841848.

Trimble, R. M., and W. G. Wellington. 1980. Oviposition stimulant associated with fourth-instar larvae of Aedes togoi (Diptera: Culicidae). J. Med. Entomol. 17: 509514.

Van Dam, A. R., and W. E. Walton. 2008. The effect of predatoryfish exudates on the ovipositional behavior of three 
mosquito species: Culex quinquefasciatus, Aedes aegypti and Culex tarsalis. Med. Vet. Entomol. 22: 399404.

Wachira, S. W., M. Ndung'u, P. G. Njagi, and A. Hassanali. 2010. Comparative responses of ovipositing Anopheles gam biae and Culex quinquefasciatus females to the presence of Culex egg rafts and larvae. Med. Vet. Entomol. 24: 369374

Waliwitiya, R., C. J. Kennedy, and C. A. Lowenberger. 2009. Larvicidal and oviposition-altering activity of monoterpenoids, trans-anithole and rosemary oil to the yellow fever mosquito Aedes aegypti (Diptera: Culicidae). Pest Manage. Sci. 65: 241248

Walton, W. E., A. R. Van Dam, and D. A. Popko. 2009. Ovipositional responses of two Culex (Diptera: Culicidae) species to larvivorous fish. J. Med. Entomol. 46: 13381343.

Warikoo, R., N. Wahab, and S. Kumar. 2011. Oviposition-altering and ovicidal potentials of five essential oils against female adults of the dengue vector, Aedes aegypti L. Parasitol. Res. 109: 1125 1131.

Wasserberg, G., N. Bailes, C. Davis, and K. Yeoman. 2014 Hump-shaped density-dependent regulation of mosquito oviposition site-selection by conspecific immature stages: theory, field test with Aedes albopictus, and a meta-analysis. PLoS ONE 9: e92658.

Wasserberg, G., L. White, A. Bullard, J. King, and R. Maxwell. 2013. Oviposition site selection in Aedes albopictus (Diptera: Culicidae): are the effects of predation risk and food level independent? J. Med. Entomol. 50: 11591164.

Wong, J., S. T. Stoddard, H. Astete, A. C. Morrison, and T. W. Scott. 2011. Oviposition site selection by the dengue vector Aedes aegypti and its implications for dengue control. PLoS Negl. Trop. Dis. 5: e1015.

Xue, R.-D., D. R. Barnard, and A. Ali. 2001. Laboratory and field evaluation of insect repellents as oviposition deterrents against the mosquito Aedes albopictus. Med. Vet. Entomol. 15: 126131.

Yee, D. A., M. G. Kaufman, and S. A. Juliano. 2007. The significance of ratios of detritus types and micro-organism productivity to competitive interactions between aquatic insect detritivores. J. Anim. Ecol. 76: 11051115.

Zahiri, N., and M. E. Rau. 1998. Oviposition attraction and repellency of Aedes aegypti (Diptera: Culicidae) to waters from conspecific larvae subjected to crowding, confinement, starvation or infection. J. Med. Entomol. 35: 782787.

Zahiri, N., M. E. Rau, and D. J. Lewis. 1997a. Oviposition responses of Aedes aegypti and Ae. atropalpus (Diptera: Culicidae) females to waters from conspecific and heterospecific normal larvae and from larvae infected with Plagiorchis elegans (Trematoda: Plagiorchiidae). J. Med. Entomol. 34 565568

Zahiri, N., G. B. Dunphy, and M. E. Rau. 1998. Serum composition of Aedes aegypti (Diptera: Culicidae) larvae and the production of an oviposition repellent are influenced by infection with the entomopathogenic digenean Plagiorchis elegans (Trematoda: Plagiorchiidae), starvation, and crowding. J. Med. Entomol. 35: 162168

Zahiri, N., M. E. Rau, D. J. Lewis, and S. Khanizadeh. 1997b. Intensity and site of Plagiorchis elegans (Trematoda: Plagiorchiidae) infections in Aedes aegypti (Diptera: Culicidae) larvae affect the attractiveness of their waters to ovipositing, conspecific females. Environ. Entomol. 26: 920923.

Zahiri, N. S., and M. S. Mulla. 2005. Non-larvicidal effects of Bacillus thuringiensis israelensis and Bacillus sphaericus on oviposition and adult mortality of Culex quinquefasciatus Say (Diptera: Culicidae). J. Vector Ecol. 30: 155162

Zettel Nalen, C. M., S. A. Allan, J. J. Becnel, and P. E. Kaufman. 2013. Oviposition substrate selection by Florida mosquitoes in response to pathogen-infected conspecific larvae. J. Vector Ecol. 38: 182187.

Zuharah, W. F., and P. J. Lester. 2010. Can adults of the New Zealand mosquito Culex pervigilans (Bergorth) detect the presence of a key predator in larval habitats? J. Vector Ecol. 35: 100105 . 